\title{
Corrosion Characteristics of Boiler Tube in Municipal Incinerators
}

\author{
Jun-ichi Sakai and Iwao Matsushima \\ Technical Research Center, Nippon Kokan K. K.*
}

\begin{abstract}
Corrosion characteristics of steels by flue gases and accumulated deposits in municipal incinerators have been studied by installing a corrosion test probe in the heat recovery unit. A series of laboratory study was carried out to analyze the effects of factors entering corrosion. Corrosion rates depend much on the temperature and increase sharply above $350-400^{\circ} \mathrm{C}$. Additions of chromium up to $18 \%$ are either ineffective or detrimental. Hot dip aluminizing is fairly effective in reducing corrosion. The corrosion rate decreases with time following the parabolic rate law indicating the protective nature of the scale formed on the surface. The presence of oxygen, chlorides and the deposits are essential for the characteristic severe corrosion to take place. The role of the deposits is presumably to supply chlorides and heavy metal compounds to the metal surface.
\end{abstract}

\section{Introduction}

The flue gas from municipal refuse incinerators imparts a new aspect to flue gas corrosion. The well documented corrosive nature of flue gas from coal or oil fired boilers is associated with sulfur oxides and vanadium compounds. The flue gas from incinerators in addition to sulfur oxides contains chlorine, chlorides and various metal compounds released mostly from plastics in the waste. They tend to deposit on the surface of the heat recovery unit and cause serious corrosion. ${ }^{1-9)}$

The present study was undertaken to learn corrosion characteristics of steels in the flue gas from incinerators by means of plant tests and laboratory studies. Although plant tests are troublesome, particularly when the heat transfer surface is involved, they are essential in exploring corrosion in the relatively new and unknown environment. The early part of the laboratory study was directed to reproduce incinerator corrosion as to the corrosion rate, corroded surface, and corrosion products with reference to the plant-test specimens. On obtaining satisfactory reproduction, the next step was to determine the effect of each factor on the severity of corrosion.

\section{Experimental}

\subsection{Plant Probe Tests}

The plant tests were carried out by installing a corrosion probe in the heat recovery unit. The unit was located between the furnace and the electrostatic precipitator of a municipal incinerator as

* 1-1, Minami-watarida, Kawasaki-ku Kawasaki 210, Japan shown in Fig. 1. The corrosion probe is illustrated in Fig. 2. Ten to twenty specimens each measuring $25.4 \mathrm{~mm}$ in diameter and $50 \mathrm{~mm}$ long were lapjointed to make a 500 to $1000 \mathrm{~mm}$ long tube and were mounted on the exposure apparatus. The outer surface of the tube was exposed to the test environment while the inner surface was cooled by air, the amount of which was automatically adjusted by a temperature control system to maintain the outer surface at a prescribed temperature in the range of 200 to $500^{\circ} \mathrm{C}$. The temperature was measured at five locations on the outer surface with thermocouples. The caster lined part of the probe was protected by introducing cooling water.

Specimens tested were a commercial grade carbon steel (STB 35), Cr-Mo steels (STPA 22, 23, 24, 25 and 26), type 304 stainless steel, hot dip aluminized steel, aluminum and titanium. The thickness of the aluminum coating was approximately 50 to 100 microns. The surface of the specimens was finished by mechanical grinding except for the aluminized steel which was used as hot dipped. The corrosion rates were estimated by weight losses.

\subsection{Compositions of Scales and Deposits}

Chemical, electron microprobe and X-ray diffraction analyses were carried out on the corrosion product scales and deposits collected on the corrosion probe in order to determine their bulk and local compositions.

\subsection{Laboratory Studies}

While the probe tests reflect the overall corrosiveness of the environment, the role of the individual factors on corrosion should be studied in 


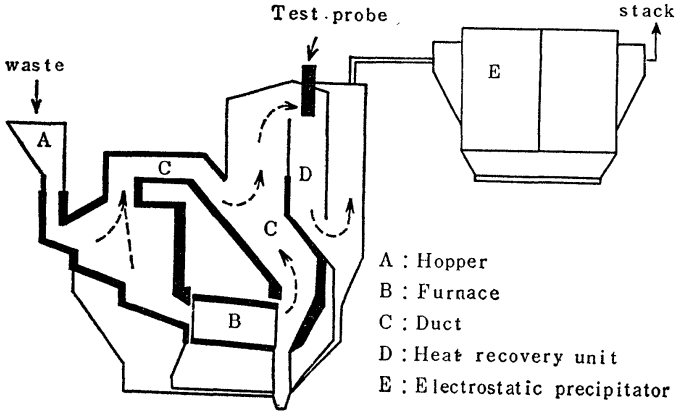

Fig. 1. Simplified illustration of the incinerator showing the test location.

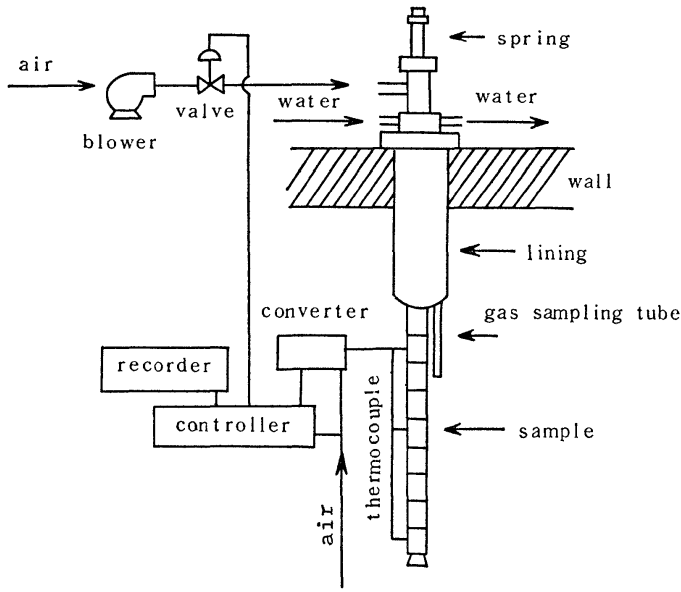

Fig. 2. Test probe.

the laboratory under varied experimental conditions.

Metal specimens measuring $30 \times 7 \times 3 \mathrm{~mm}$ were placed in porcelain boats located in quartz tube passing through the furnace. The furnace had a preheating section where the inlet gas was heated up to prescribed temperatures. The standard synthetic flue gas consisted of $250 \mathrm{ppm} \mathrm{SO}_{2}$, $2000 \mathrm{ppm} \mathrm{HCl}, 30 \% \mathrm{H}_{2} \mathrm{O}$ and air. The flow rate was $10 \mathrm{l} / \mathrm{hr}$. This condition was chosen based on the preliminary tests and represented the very severe environment encountered in the incinerator. Specimens were buried in the deposits collected on the probe exposed in the plant. Test specimens were a commercial grade carbon steel (SS 41), some Cr-Mo steels, and types 430 and 304 stainless steels. They were mechanically finished and degreased before testing. The corrosion rates were estimated in terms of weight loss.

\section{Results and Discussion}

3.1 Probe Test

The corrosion rate of STB 35 is shown in Fig.

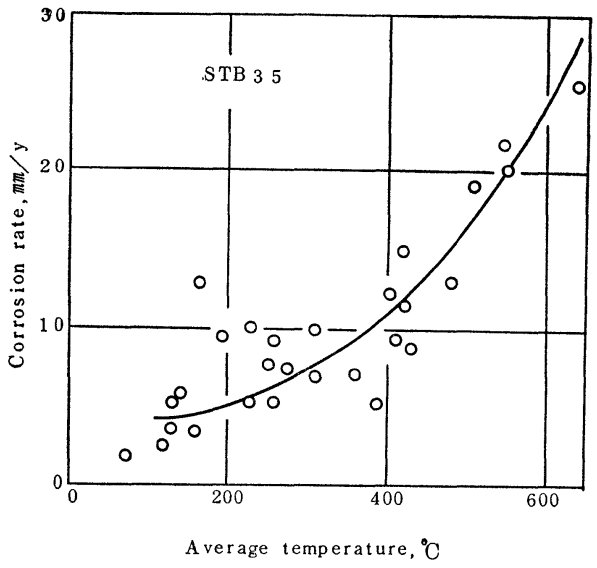

Fig. 3. Effect of temperature on the corrosion rate of carbon steel, probe test, 192 hours.

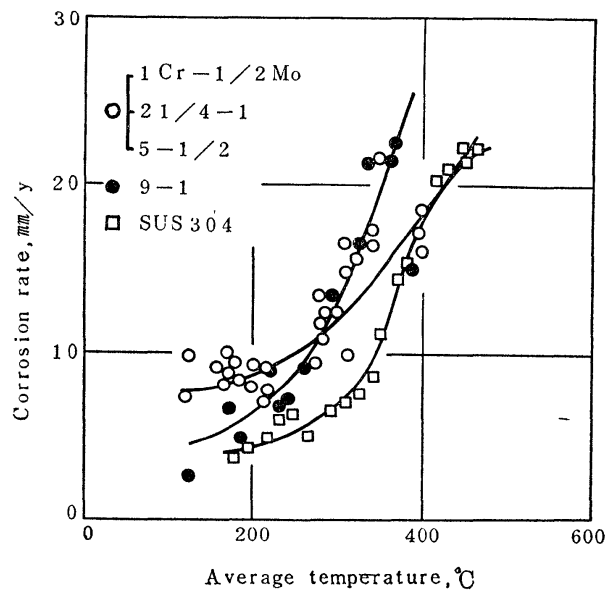

Fig. 4. Effect of temperature on the corrosion rate of $\mathrm{Cr}-\mathrm{Mo}$ steels, probe test, 192 hours.

3 as a function of temperature. Data were obtained by 192 hours exposure and expressed in terms of millimeter penetration per year $(\mathrm{mm} / \mathrm{y})$. Since the corrosion vs. time curve followed the parabolic rate law as will be shown later, the corrosion rates plotted in Fig. 3 would be greater than the values which would be obtained by one year exposure. The corrosion rate depended on the temperature and increased sharply above 350 to $400^{\circ} \mathrm{C}$. The reported values ${ }^{1,10,11)}$ of the critical temperature above which the corrosion rate is exceedingly high scatter in the range of 260 to $500^{\circ} \mathrm{C}$ depending on the experimental conditions.

Similar critical temperatures were also found for $\mathrm{Cr}-\mathrm{Mo}$ and stainless steels. Data for $\mathrm{Cr}-\mathrm{Mo}$ steels and type 304 stainless steel are plotted in Fig. 4. Apparently, the chromium content affected the corrosion behavior as indicated by three different 


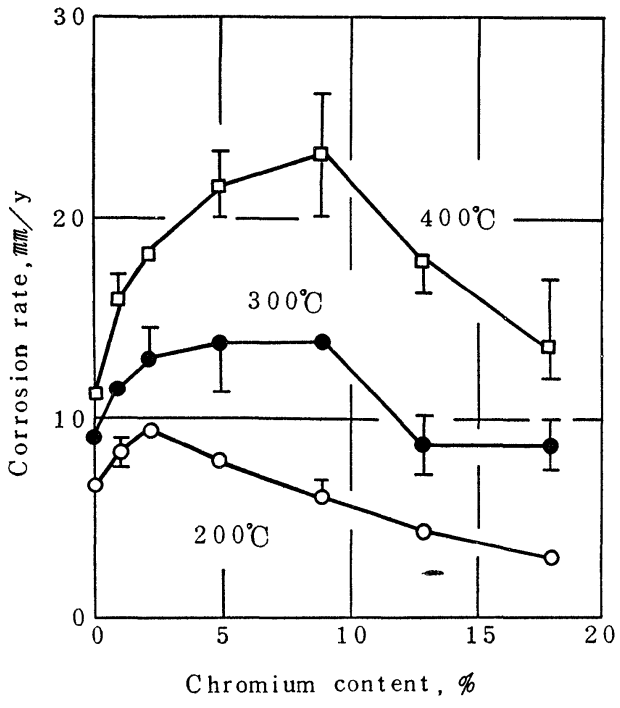

Fig. 5. Effect of $\mathrm{Cr}$ on corrosion, probe test, 192 hours.

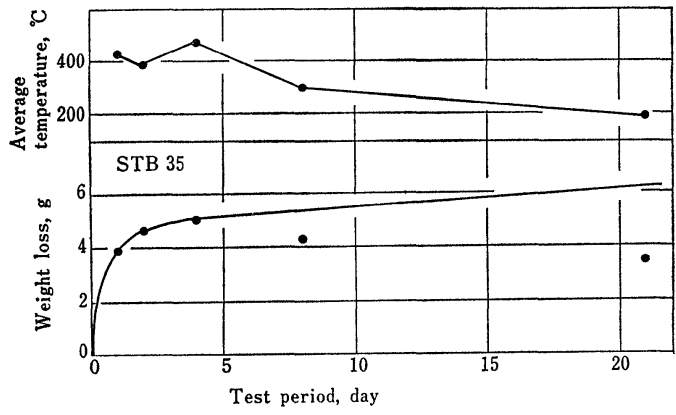

Fig. 6. Corrosion vs. time relation of carbon steel obtained in the field test.

curves for $0-5 \% \mathrm{Cr}, 9 \% \mathrm{Cr}$ and $18 \% \mathrm{Cr}-8 \% \mathrm{Ni}$ steels. However, depending upon the temperature, $\mathrm{Cr}$ additions were not necessarily beneficial. Figure 5 shows the effect of chromium on corrosion at three different temperatures. At $200^{\circ} \mathrm{C}$, the corrosion rate increased up to $2.25 \% \mathrm{Cr}$ and then decreased with increase of Cr. At $300^{\circ} \mathrm{C}$, the rate increased up to $2.25 \% \mathrm{Cr}$ but it remained constant in the chromium content range between $2.25 \%$ and $9 \%$. Further increase of the $\mathrm{Cr}$ content decreased the corrosion rate. The corrosion resistance of the $18 \% \mathrm{Cr}$ steel, however, was no better than that of mild steel. At $400^{\circ} \mathrm{C}$, the corrosion rate reached a maximum at $9 \% \mathrm{Cr}$ and again the $18 \% \mathrm{Cr}$ steel had no advantage over mild steel. It is obvious that additions of chromium are either detrimental or ineffective in this environment except for in the low temperature region. The detrimental effect of chromium was more pronounced at higher tempera-

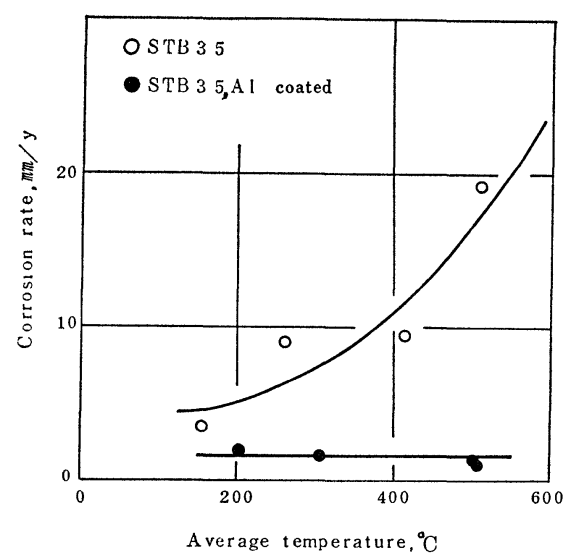

Fig. 7. Effect of aluminizing on corrosion of carbon steel, probe test, 192 hours.

O STB 35, — STB 35, Al coated.

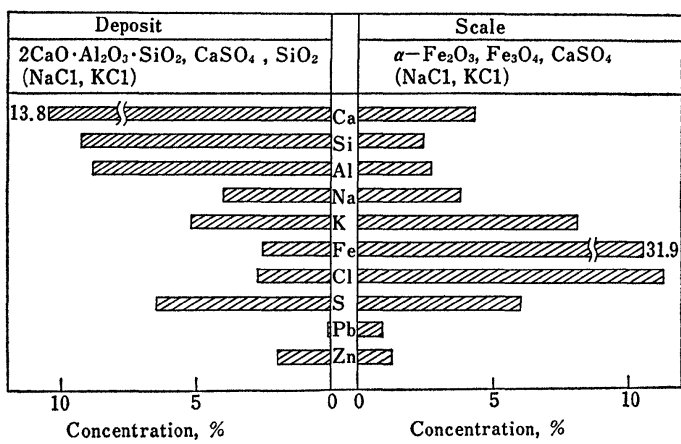

Fig. 8. Analyses of scale and deposit formed on the test probe. Samples were collected from specimens exposed for 24-504 hours.

tures. It is interesting to note that $\mathrm{Cr}$ is not beneficial in $\mathrm{HCl}$ and $\mathrm{Cl}_{2}$ gas. ${ }^{121}$

Figure 6 shows the weight loss vs. time curve obtained for STB 35 by the probe tests. Unfortunately, the temperature was not constant but decreased with time due to the accumulation of thick deposits on the specimen surface. It was impossible, therefore, to find out the main factor that decreased the corrosion rate with time; it could be attributed either to the temperature drop, insulation from corrosive substances by the thick layer of accumulated deposits or by the protective scale formation. The laboratory study, however, showed that the corrosion rate decreased with the scale formation and that it increased in the presence of deposits. Therefore, it was concluded that the decrease in corrosion rate in Fig. 6 was due both to the temperature drop and to the scale formation.

Some tests were also conducted on aluminum and titanium. They showed good corrosion re- 


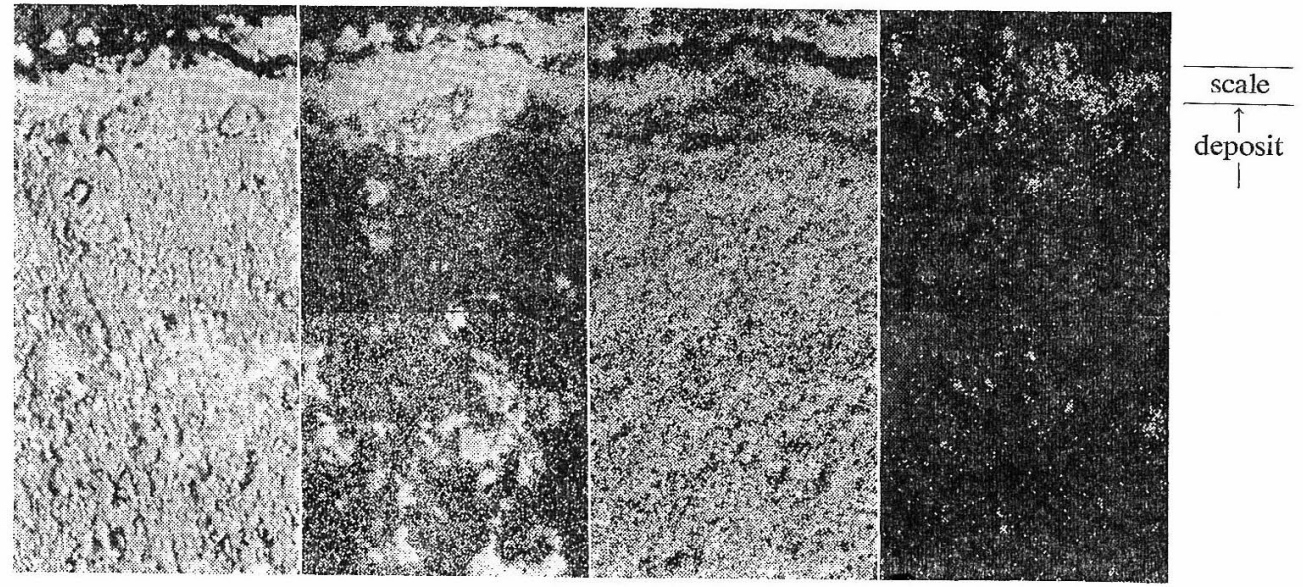

BEI

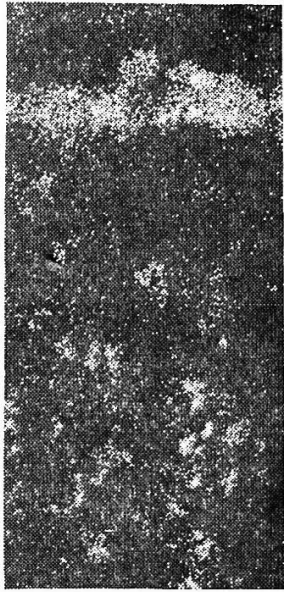

$\mathrm{Na}$
$\mathrm{Fe}$

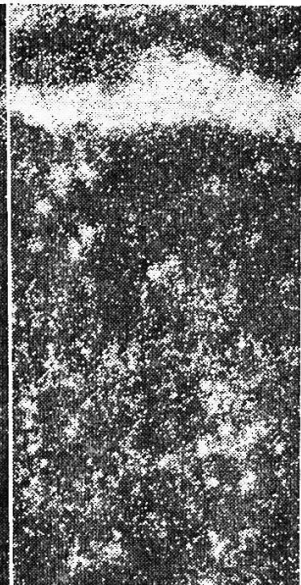

$\mathrm{Cl}$
0

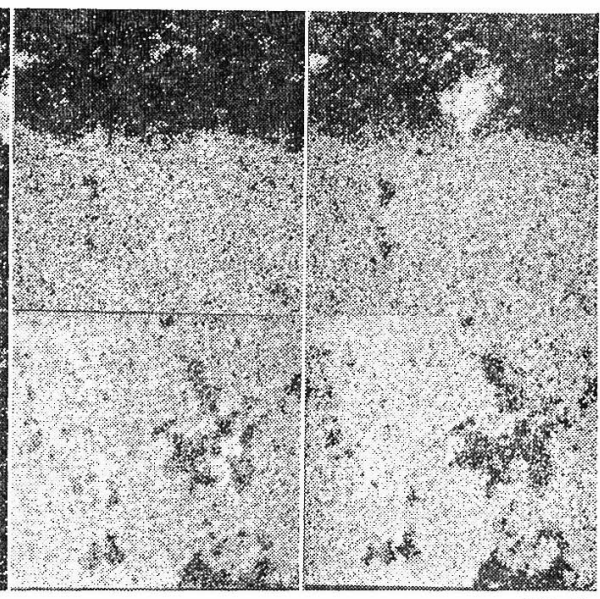

$50 \mu$

Fig. 9. Distribution of elements at the interface of scale/deposit. Cross sectional survey by EPMA.

sistance only at low temperatures, i.e., below $350^{\circ} \mathrm{C}$. The most resistant material throughout the temperature range of $200^{\circ} \mathrm{C}$ to $500^{\circ} \mathrm{C}$ was the hot dip aluminized steel as shown in Fig. 7. Hot dip aluminizing improved the corrosion resistance 5 to 10 times over the bare steel. It was confirmed by cross sectional analyses that the aluminum layer was still present after the test. The reason why the aluminized steel is more resistant than aluminum metal is not clear, but a possible explanation is that while the $\mathrm{Al}_{2} \mathrm{O}_{3}$ layer on aluminum spalls off, it tends to adhere on the steel surface. The corrosion resistance of type 304 was also improved by hot dip aluminizing.

\subsection{Compositions of Scales and Deposits}

A scale layer of corrosion products was formed on the surface of the specimens tested in the incinerator. The scale layer in turn was covered by a thick layer of deposits from the environment. The thickness of the latter was 20 to $40 \mathrm{~mm}$ after 192 hours exposure. The results of X-ray diffraction and chemical analyses of the specimens exposed for 24 to 504 hours are summarized in Fig. 8. The exposure time apparently had no effect on the composition of the scales and the deposits. Besides the compounds listed in the figure, there was some indication of the presence of $\mathrm{FeCl}_{2}$ in the scale. It should be noted that the scale contained rather high amount of sulfur and chlorides, $6 \%$ and $11 \%$, respectively. These values agree with those obtained by Miller et $a l^{2}{ }^{2}$ The cross sectional distribution of the elements in the scales and deposits are shown in Fig. 9. Fe, $\mathrm{O}, \mathrm{Na}, \mathrm{Pb}$ and $\mathrm{Cl}$ were enriched in the scale layer and $S, K$ and $O$ were enriched in the deposit layer. No bisulfates and pyrosulfates were detected in spite of the sugges- 


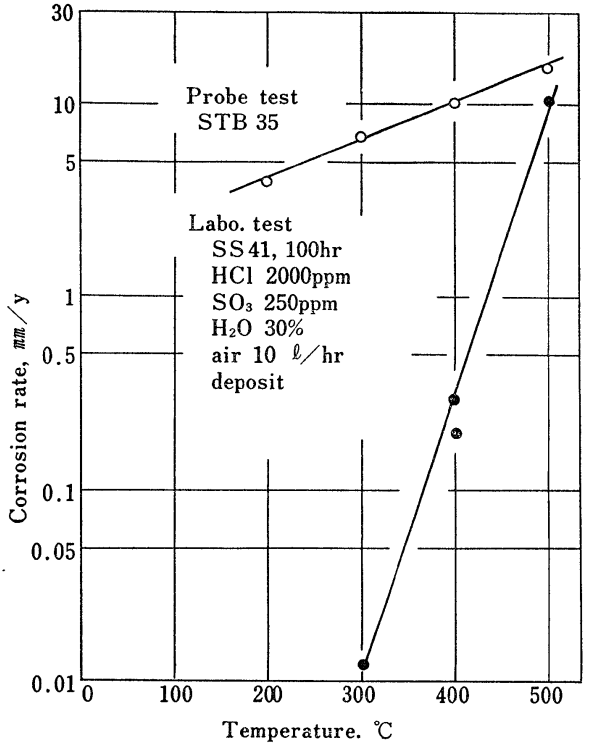

Fig. 10. Comparison of the effect of temperature between field and laboratory tests.

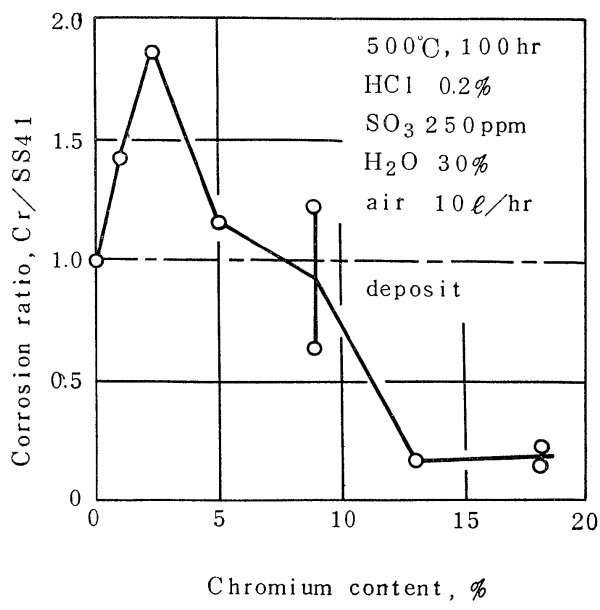

Fig. 11. Effect of $\mathrm{Cr}$ on corrosion, laboratory test, $500^{\circ} \mathrm{C}, 100$ hours.

tions of Miller et al. ${ }^{13,14)}$ who claimed that these compounds were the main corrosive substances due to their low melting points.

\subsection{Laboratory Experiments}

A series of laboratory study has been conducted to learn the effects of various factors potentially influencing corrosion, particularly those of $\mathrm{HCl}, \mathrm{SO}_{3}$ and the deposits. Figure 10 compares the effect of temperature found in the plant and in the laboratory. The laboratory results showed that the corrosion rate increased logarithmically as the temperature rose. The difference in the corrosion rates obtained in the plant and laboratory can be at-

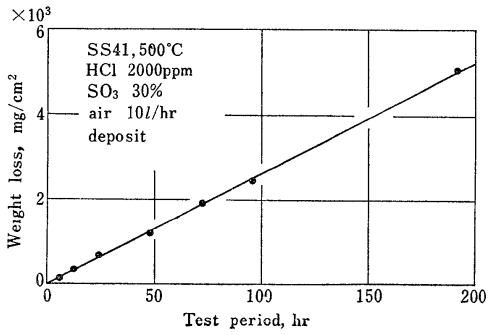

Fig. 12. Corrosion vs. time relation of carbon steel observed in the laboratory, $500^{\circ} \mathrm{C}$.

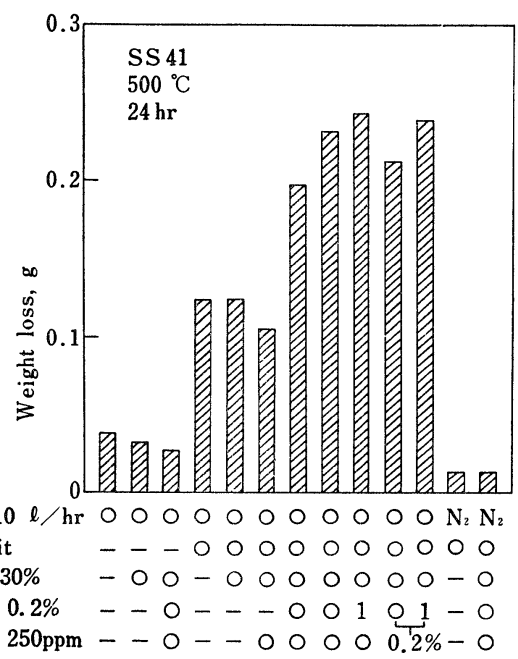

Fig. 13. Effect of environmental factors on corrosion.

tributed to either one or both of the facts that 1) the heat transfer condition is present only in the plant, and 2) the temperature control is less sufficient in the field. The latter should be most suspected since the corrosion rates agreed at $500^{\circ} \mathrm{C}$ at which the temperature control in the plant was most reliable. Figure 11 shows the effect of $\mathrm{Cr}$ additions on corrosion resistance at $500^{\circ} \mathrm{C}$ as determined by the laboratory test conducted for 100 hours. Although the laboratory results also showed that the additions of chromium were not practically beneficial, the maximum corrosion rate appeared at a lower chromium content than in the plant; the chromium content at which the corrosion rate was maximum at $500^{\circ} \mathrm{C}$ in the laboratory corresponded to that at 200 to $300^{\circ} \mathrm{C}$ in the plant. This fact suggests that the actual temperature in the plant tests were higher than the prescribed temperature.

The corrosion vs. time relation of the mild steel at $500^{\circ} \mathrm{C}$ was determined by laboratory tests as shown in Fig. 12. Apparently, the relation fol- 
lows the parabolic rate law. This fact suggests that the corrosion rate is controlled by diffusion of some reacting species through the surface film. The apparent activation energy obtained by using the data in Fig. 10 in $\log k$ vs. $1 / T\left({ }^{\circ} \mathrm{K}\right)$ plot is 30 $\mathrm{kcal} / \mathrm{mol}$, which is a reasonable value for diffusion processes. Using the rate law, the plot in Fig. 12 can be extrapolated to obtain a corrosion loss of $0.6 \mathrm{~mm}$ in the first one year. Similarly, the corrosion data obtained by the plant test for STB 35 at $400^{\circ} \mathrm{C}$ can be extrapolated to one year to give $0.5 \mathrm{~mm}$. The similar value for the hot dip aluminized steel is 0.05 to $0.1 \mathrm{~mm}$.

The effects of corrosive factors such as $\mathrm{HCl}$, $\mathrm{SO}_{3}$ and deposits were examined separately. Figure 13 shows the weight loss of carbon steel tested at $500^{\circ} \mathrm{C}$ for $24 \mathrm{hr}$ in various combinations of factors. The factors considered were air, deposits, water, $\mathrm{HCl}$ and $\mathrm{SO}_{3}$. At this temperature, oxidation by air was small and an addition of $30 \%$ water or $30 \% \mathrm{H}_{2} \mathrm{O}+0.2 \% \mathrm{HCl}+250 \mathrm{ppm}$ $\mathrm{SO}_{3}$ did not increase the corrosion rate. The presence of the deposits under air, air $+\mathrm{H}_{2} \mathrm{O}$ or air $+\mathrm{H}_{2} \mathrm{O}+\mathrm{SO}_{3}$ increased the corrosion rate about 3 times. The combination of the deposits and $\mathrm{HCl}$ showed the greatest corrosivity and the corrosion rate was about 5 times of that obtained with air only. Further increase of $\mathrm{HCl}$ in gas up to 5 times did not increase corrosion accordingly.

Additions of $\mathrm{SO}_{3}$ to the $\mathrm{HCl}$-deposit system further increased corrosion but the effect was only minor. The relative ineffectiveness of $\mathrm{SO}_{3}$ in accelerating corrosion indicates that the presence of bisulfate and pyrosulfate are of less significance.

Since the deposits alone increase corrosion and $\mathrm{HCl}$ alone does not, the deposits are not simply the source of $\mathrm{Cl}$ as chlorides. The characteristic substance in the deposits is zinc. Less than $1 \%$ lead and cadmium were also found in the deposits. In the supplementary laboratory experiments using synthetic deposit consisting of sulfate and chlorides of sodium and potassium, it was found that additions of $\mathrm{PbCl}_{2}$ made the deposit very corrosive. Thus, heavy metals in the deposits give a significant consequences in the corrosion mechanism.

The experimental results also show that the presence of air (oxygen) is necessary for any significant amount of corrosion to take place by the corrosive substances, indicating that oxidation also plays an essential part in the corrosion mechanism. Since both chloride and oxygen are involved in the accelerating effect, the mechanism includes conversion of oxides to chlorides or vice versa in the cor- rosion product layer affecting its protectiveness. However, further study is necessary before any specific mechanism be postulated.

\section{Conclusions}

From the results obtained in the present study, the following conclusions can be drawn:

1) The probe tests show that corrosion is particularly severe above 350 to $400^{\circ} \mathrm{C}$. At $300^{\circ} \mathrm{C}$, carbon steels are fairly resistant while at $500^{\circ} \mathrm{C}$ 18-8 stainless steel, aluminum and titanium are not resistant.

2) Additions of chromium to steel are generally detrimental or ineffective as observed in probe and laboratory specimens.

3) The aluminized steel is fairly resistant in the temperature range 200 to $500^{\circ} \mathrm{C}$ under practical conditions.

4) The corrosion rate decreases with time according to the parabolic rate law at a constant temperature as realized in the laboratory. This suggests that diffusion of some species controls the rate. The apparent activation energy is $30 \mathrm{kcal} / \mathrm{mol}$. In practice accumulation of deposits may change the temperature with time so that the parabolic rate is not followed precisely.

5) The corrosion mechanism involves the activities of chloride, oxygen and heavy metals.

(Received September 20, 1975)

\section{Reference}

1) P. D. Miller \& H. H. Krause: Corrosion, 27, 31 (1971).

2) P. D. Miller: U. S. Environmental Protection Agency Report SW-72-3-3 (1972).

3) A. J. Elshunt: Int'l Tagung, Korrosionen in Müll u. Abfallver brennungs Anlagen, 1970 (Düsseldorf).

4) F. Nowak: Combustion, 1968, Nov., 32.

5) G. McGill: Preprint 64th meeting Air Pollution Control Association, 1971, June (Atlantic City).

6) J. D. Palmer: Can. Chemical Processing, April, 79 (1971).

7) J. W. Regan: Proc. 1970 Nat'l Incinerator Conference, ASME, 216 (Cincinnati).

8) F. Nowak: ibid, p. 86.

9) H. Hilsheimer: ibid, p. 93.

10) Y. Hayashi \& Y. Takahashi: Karyoku Hatsuden, 21, 489 (1970).

11) Y. Takahashi: Hitachi Hyoron, 52, 1054 (1970).

12) K. Fujita, H. Onoue \& K. Sakiyama: Boshoku Gijutsu, 19, 340 (1970).

13) P. D. Miller, H. H. Krause, J. Zupan \& W. K. Body: Corrosion, 28, 222 (1972).

14) P. D. Miller, H. H. Krause, D. A. Vaughan \& W. K. Boyd: ibid, 28, 274 (1972). 